\title{
DIREITO DO TRABALHO E TEORIA SOCIAL CRÍTICA: UM DIÁLOGO INDISPENSÁVEL ENTRE ESTE CAMPO DO DIREITO E OS DEMAIS SABERES SOCIAIS
}

\section{LABOR LAW AND SOCIAL CRITICAL THEORY: AN \\ INDISPENSABLE DIALOGUE BETWEEN THIS LAW \\ FIELD AND OTHER SOCIAL KNOWLEDGE}

RESUMO: O artigo objetiva demonstrar a necessidade de o Direito do Trabalho dialogar com os outros campos dos chamados saberes sociais, ou culturais que lidam com o mundo do trabalho. Deste diálogo, resultará, primeiro, o desvendamento ideológico do seu objeto: o trabalho contraditoriamente livre/subordinado. Por meio de evidências empíricas e analíticas, demonstrará, em seguida, que o mesmo se encontra refutado. No sentido de promover uma inversão na perspectiva analítica para compreensão e redefinição do objeto deste campo do direito, reivindica um diálogo entre os movimentos coletivos tipicamente trabalhistas e os demais movimentos sociais. Um diálogo que aproxima a teoria jurídico-trabalhista crítica das teorias dos movimentos sociais. Por este caminho é possível reconhecer que o Direito do Trabalho é fruto de uma época datada e não trans-histórica. Época em que aparece e se legitima, por meio do Estado Moderno, o modo de produção capitalista e a subordinação da força do trabalho ao capital. Problematizar, refutar e propor gnosiologicamente novos fundamentos para este campo do direito exige este diálogo.

Palavras-chave: Teoria Social Crítica. Teoria jurídicotrabalhista crítica. Trabalho livre/subordinado. Teoria dos movimentos sociais.
ABSTRACT: The paper aims to demonstrate the need for labor law dialogue with other fields of knowledge called social or cultural dealing with the world of work. This dialogue will result first, the ideological unmasking of its object: the contradictorily free/subordinate work. Through empirical and analytical evidence, demonstrate then that it is rejected. In order to promote investment in analytical perspective for understanding and redefining the object of this field of law, claims a dialogue between the typically labor collective movements and other social movements. A dialogue that brings the legal-labor theory critique of theories of social movements. By this way it is possible to recognize that labor law is the result of a dated time and not trans-historical. Time that appears and is legitimated through the modern state, the capitalist mode of production and the subordination of labor to capital strength. Problematize, refute and propose gnosiologicamente new foundations for this field of law requires this dialogue.
Keywords: Critical Social Theory. Legal and labor critical theory. Free/subordinate work. Theory of social movements.

\footnotetext{
${ }^{1}$ Doutor em Direito pela Universidade de Deusto/ES. Professor dos programas de graduação e de pós-graduação da Faculdade de Direito da Federal de Pernambuco. Professor da UNINASSAU. Membro da Academia Brasileira e Pernambucana de Direito do Trabalho. E-mail: everaldo.andrade@ufpe.br.

${ }^{2}$ Mestre e Doutora em Direto pela Universidade Federal de Pernambuco. Professora Assistente da Universidade de Pernambuco. Professora da Pós-Graduação lato sensu da Universidade Federal de Pernambuco - UFPE. Professora da UNINASSAU e da Faculdade Damas. Membro da Academia Pernambucana de Direito do Trabalho e do Instituto Ítalobrasileiro de Direito do Trabalho.
} 


\section{INTRODUÇÃO}

Este artigo pretende demonstrar, primeiro, a obsolescência da doutrina jurídicotrabalhista clássica, na medida em que a mesma continua elegendo como objeto do Direito do Trabalho, o trabalho contraditoriamente livre/subordinado. Do mesmo modo, quando privilegia, no âmbito das relações sindicais, os movimentos de cunho reformistas e deixa de lado aqueles que têm caracteres emancipatórios ou contra-hegemônicos.

Este perfil teórico-dogmático deixa transparecer, inicialmente, que este ramo do direito, ao eleger como seu objeto o trabalho livre/subordinado, recepcionou os fundamentos da filosofia liberal, centro de referência do Estado Moderno. Logo, não empreendeu uma revolução, no âmbito do Direito Privado, como dizem os seus autores, especialmente nos manuais. Ao contrário, serviu para legitimar um modelo de estado e de sociedade centrado na compra e venda da força de trabalho.

Procura demonstrar também que o trabalho livre/subordinado, como objeto do Direito do Trabalho, encontra-se refutado por meio de evidências empíricas e analíticas.

A partir de um diálogo estabelecido com os outros campos dos chamados saberes sociais ou culturais, demonstra que o trabalho livre/subordinado, "contraponto" do trabalho escravo/servil, não é um fenômeno transhistórico, mas um fenômeno datado. Ele surge, legitima-se e se universaliza na Era Moderna.

Por meio deste diálogo demonstra também que a subordinação da força do trabalho ao capital produz um nível de controle e de apropriação da subjetividade daquele que venda sua força de trabalho jamais vista em épocas anteriores. Por seu turno, institui rituais de sofrimento e morte lenta no trabalho muito mais cruel. Sobretudo, por decorrer do avanço da teoria organizacional que vem possibilitando, por meio da racionalização e das novas tecnologias, um nível de produtividade sem precedentes. 
Um diálogo que aproxima os estudos envolvidos com as relações sindicais ou coletivas de trabalho às lutas simultaneamente reformistas e emancipatórias, o que se torna possível quando se estabelece a sua aproximação com os movimentos sociais e as teorias dos movimentos sociais.

Deixa, por fim, transparecer que os fundamentos clássicos do Direito Trabalho estão refutados, porque refutado se encontra o seu próprio objeto - o trabalho livre/subordinado -, conforme adiante se comprovará.

\section{O PARADIGMA TRABALHO LIVRE/SUBORDINADO COMO OBJETO DO DIREITO DO TRABALHO}

A narrativa desencadeada pela doutrina clássica encontra-se sedimentada nos seguintes argumentos: antigamente, havia trabalho escrevo e servil. A partir da Revolução Industrial e com o advento do Estado Moderno - uma vitória da burguesia, que promoveu a sua ascensão ao poder, depois de haver destronado o Absolutismo Monárquico, em que os poderes se encontravam nas mãos do clero e da nobreza -, aparece o trabalho ao mesmo tempo e contraditoriamente livre e subordinado, para estabelecer um contraponto e sepultar às relações de trabalho vivenciadas anteriormente - escravas/servis.

Diz que o Direito do Trabalho, centrado na proteção deste tipo de labor, foi capaz de desencadear uma revolução no âmbito do Direito Privado, na medida em que reconheceu a existência de relações contratuais marcadamente assimétricas, ao contrário das demais relações contratuais privadas. Logo, não poderia ter como base o binômio liberdade/igualdade típico do individualismo nascente, que pressupunha liberdade e igualdade daquelas mesmas partes contratantes.

Era, pois, imprescindível construir uma versão teórica capaz de conceder superioridade jurídica a um dos sujeitos desta relação - o empregado -, para compensar a superioridade econômica do outro sujeito - o empregador. Este pressuposto foi erigido 
através do Princípio da Proteção que, reconhecendo aquela assimetria, procurou cercar o empregado de certas garantias, a fim de inibir a superioridade patronal.

Se se trata de uma relação jurídica assimétrica, em que o um dos sujeitos - o empregador - admite, assalaria, detém o poder de comando ou disciplinar; e, do outro, aquela que fica jurídica, econômica e psicologicamente àquele subordinado, o Direito do Trabalho deveria construir princípios próprios dirigidos à elaboração de normas constitucionais e infraconstitucionais com caracteres de irrenunciabilidade, inderrogabilidade, indisponibilidade e ordem pública capazes de compensar aquela desigualdade ou assimetria entre os sujeitos da relação de emprego.

O discurso jurídico-trabalhista se instituiu e segue este caminho, há mais de cem anos.

O que se pode inferir desta narrativa é que, em primeiro lugar, este modelo de sociabilidade se universaliza e se legitima com o modo de produção capitalista centrado na subordinação da força do trabalho ao capital.

Por isso, não se trata de um fenômeno transhistórico, mas datado. O trabalho vendido, comprado e separado da vida passa a se constituir como lócus privilegiado da sociabilidade e o a priori das teorizações no campo da sociologia clássica, em geral, e do Direito do Trabalho, em particular. Neste contexto, um novo sistema jurídico aparece legitimado e universalizado.

Estas as razões pelas quais se torna correta a afirmação lançada por João Maurício Adeodato (2012): o direito dogmaticamente organizado é produto da Modernidade. Tem razão porque a burguesia, o modo de produção capitalista e a subordinação da força do trabalho ao capital não vieram para ser hegemônicas num determinado país ou numa determinada região, vieram para ser hegemônica no mundo.

O Direito do Trabalho passou a assim a eleger como seu objeto o trabalho livre/subordinado que se instituiu no interior das organizações produtivas e estabeleceu uma ruptura sem precedentes, diante dos mecanismos de sociabilidade estruturados nas 
experiências anteriores ao advento da sociedade moderna. Uma forma de sociabilidade, repita-se, que se legitima e se universaliza, passa a se constituir como lócus privilegiado no mundo da vida e a priori das teorizações no campo da sociologia clássica (MARX, WEBER E DURKHEIM).

\title{
3 A DESCONSTRUÇÃO DO PARADIGMA TRABALHO SUBORDINADO COMO OBJETO DO DIREITO DO TRABALHO
}

Neste capítulo, o artigo problematiza e refuta o trabalho livre/subordinado como objeto deste campo do direito, a partir de evidências empíricas e analíticas presentes em vários estudos interdisciplinares.

\subsection{A Questão Metodológica}

Assinala Enoque Feitosa que "a questão metodológica é central em qualquer campo do conhecimento que pretenda constituir qualquer empreendimento naquilo que se convencionou chamar de ciência" (FEITOSA, 2012, p. 133).

Mesmo no contexto do método dialético - concreto-abstrato-concreto -, a produção de conhecimento, por meio da ciência, se torna um exercício de abstração. Para ele, da aplicação do método dialético, percebe-se uma sólida compreensão do fenômeno jurídico ou

\begin{abstract}
o direito como categoria inserida na totalidade social e como uma manifestação dessa totalidade, que se constitui, em razão dos conflitos sociais, e não por cima e por fora deles, como forma de permitir sua solução "controlada" por cima. Por isso só o método cuja pretensão é captar a realidade em seu movimento é que pode dar conta não só da descoberta, mas de explicar a forma jurídica (FEITOSA, 2012, p. 149).
\end{abstract}

Mesmo na versão defendida por Karl Popper, da sua epistemologia, lógica da pesquisa científica ou na teoria do método científico, que se afasta dos positivistas - por entender que eles supõem a ciência empírica em termos de um sistema de enunciados que 
satisfazem certos critérios lógicos, tais como significatividade ou verificabilidade - há um posicionamento que vai além de uma análise puramente lógica das relações entre enunciados científicos, posto que diz respeito à escolha de métodos. Admite como

característica distintiva dos enunciados empíricos a circunstância de estes serem suscetíveis de revisão: o fato de poderem ser criticados e substituídos por enunciados mais adequados e aqueles que encaram a tarefa que lhes é própria analisar a capacidade característica de a Ciência progredir e a maneira peculiar de decidir, em casos cruciais, entre sistemas teóricos conflitantes (POPPER, 1972, p. 52).

Mas, a lógica da pesquisa adotada pelos autores deste texto segue a teoria social crítica, remonta as ideias de Geuss, Horkheimer e Habermas e se inclina para o socialismo. Neste sentido, a modalidade de evidência a ser priorizada não se restringe a determinar se elas são cognitivamente aceitáveis ou não. É que as teorias tradicionais se satisfazem com as confirmações empíricas centradas no critério observação/experimentação. Na trilha da concepção crítica apontada por um dos autores deste artigo,

uma verdadeira teoria social dispõe-se a investigar as instituições e práticas sociais que os agentes exercem sobre a sociedade, mas também as convicções dos agentes sobre a sociedade, já que investiga a realidade social no sentido estrito e o saber social que forma parte da realidade. Ao contrário da teoria tradicional que não se questiona a si mesma ou a seu objeto - a teoria crítica parte de uma estrutura cognitivo-reflexiva para abordar a própria "gênesis", a própria origem da sociedade, explicar os pressupostos do próprio objeto investigado e antecipar as possibilidades de seu uso e aplicação (ANDRADE, 2005, p. 319).

Como esclarece Celso Naoto Kashiura Jr., somente no modo de produção capitalista é possível encontrar o surgimento de dois "polos de relação capital-trabalho como sujeitos de direito, como portadores de mercadorias na esfera da circulação" (KASHIURA JR, 2014, p. 206). Neste sentido, encontra-se, de um lado, um sujeito de direito "proprietário de dinheiro (e dos meios de produção) que se defronta numa relação jurídica contratual com outro sujeito de direito" (KASHIURA JR, 2014, p. 206) que é, por seu turno, aquele que é portador de sua própria força de trabalho. Para o autor, 
é essencial a esse modo de produção que o produtor direto não seja constrangido - exceto economicamente - a produzir: a união entre o produtor direto e os meios de produção - que lhe foram previamente expropriados - só pode ocorrer, então, por meio da circulação de mercadorias, de um modo tal que o próprio potencial de trabalho do produtor direto apareça como mercadoria e circule sob a forma de mercadoria na troca de equivalente. Assim, o trabalhador só fornece a sua capacidade de trabalho na medida em que recebe, na troca, uma certa quantidade de valor a ela equivalente - e o capital só obtém a força de trabalho necessária à sua ativação dos meios de produção na medida em que a compra por uma certa quantidade de valor sob a forma de dinheiro: salário (KASHIURA JR, 2014, p. 90).

Da maneira como uma das autoras deste texto tem desenvolvido suas pesquisas e seus estudos, a simetria buscada pelo Direito do Trabalho se torna impossível, porque, de saída, ter-se, como objeto deste campo do direito, o trabalho ao mesmo tempo livre e subordinada, implica reconhecer a existência de uma aporia que bate de frente com a lógica maior de Aristóteles: uma coisa não pode ser e deixar de ser, ao mesmo tempo e sob o mesmo aspecto (D'ANGELO, 2014).

A refutação a este objeto baseia-se, portanto, em evidências empíricas e analíticas. Metodologicamente porque se toda ciência se apropria de um objeto, ele só se legitima e se mantém quando suporta ou resiste à refutabilidade. E o trabalho livre/subordinado encontra-se refutado porque não resiste às evidências empíricas ou analíticas ou a ambas.

\subsection{As Evidências Empíricas}

Quando se empreende uma pesquisa na literatura que forma o vasto universo da chamada teoria jurídico-trabalhista clássica verifica-se claramente que a mesma conceitua o Direto do Trabalho como um conjunto de normas e princípios destinados à proteção do trabalho subordinado, dependente ou por conta alheia. Logo, tratar-se-ia de um ramo do direito que não veio para disciplinar qualquer relação de trabalho, mas a relação de trabalho subordinado.

Não se pode deixar de reconhecer que o Estado do Bem-estar Social, centrado no Pleno Emprego forjou, ideologia à parte, um modelo de sociabilidade de tempo previsível, 
duradouro. Acontece que, depois da crise de 70 do século passado, da chegada ao poder dos governos Margaret Thatcher e de Ronald Reagan, da Queda do Muro de Berlim, da substituição do Modelo Fordista pelo Modelo de Acumulação Flexível, aliado ao espetacular desenvolvimento das máquinas inteligentes, da tecnologia da comunicação e da informação, apareceu uma metamorfose sem precedentes no mundo do trabalho que inverteu aquela perspectiva construída no Estado do Bem-estar. Agora, a prevalência é do trabalhado clandestino e do desemprego estrutural.

Referindo-se às evidências empíricas, presentes em várias pesquisas, admite Ricardo Antunes que o mundo do trabalho sofreu, como resultados das transformações e metamorfoses em curso nas últimas décadas, um processo de desproletarização do trabalho industrial, fabril, que se traduz, de um lado, na diminuição da classe operária tradicional e, do outro, numa significativa subproletarização do trabalho, decorrente "das formas diversas de trabalho parcial, precário, terceirizado, subcontratado, vinculado à economia informal, ao setor de serviços, etc. Verificou-se uma heterogenização, complexificação e fragmentação do trabalho" (ANTUNES, 2006, p. 209-211). Para ele, há um múltiplo processo que envolve a desproletarização da classe-que-vive-do-trabalho e uma subproletarização do trabalho, convivendo, ambas, com o desemprego estrutural.

Se, de um lado, os desempregados eram, até o apogeu do Estado do Bem-estar Social, exércitos de reserva da mão de obra, agora a situação se inverte, com a chegada dos subempregados e do desemprego estrutural. Viviane Forrester retrata o drama daqueles que são obrigados a procurar emprego:

não se sabe se é cômico ou sinistro, por ocasião de uma perpétua, irremovível e crescente penúria de empregos, impor a cada um dos milhões de desempregados - e isso a cada dia útil de cada semana, de cada mês, de cada ano - a procura (efetiva e permanente) desse trabalho que não existe. Obrigá-lo a passar horas, durante dias, semanas, meses e, às vezes, anos, se oferecendo todo o dia, toda semana, todo mês, todo ano, em vão, barrado previamente pelas estatísticas (FORRESTER, 1979, p. 14).

Na mesma linha, Bauman afirma que 
os desempregados eram o exército de reserva da mão-de-obra. Temporariamente sem emprego por motivo de saúde, enfermidade ou dificuldades econômicas correntes, eles deviam ser preparados para reassumir o emprego, quando aptos - e prepará-los era, então, de um modo geral, a tarefa reconhecida e a incumbência explícita ou tácita dos poderes públicos. Já não acontece assim. Exceto nos nostálgicos e cada vez mais demagógicos textos de propaganda eleitoral, os sem emprego deixaram de ser um exército de reserva da mão-de-obra (BAUMAN, 1998, p. 50).

De acordo com recente pesquisa realizada pela OIT - Organização Internacional do Trabalho, chamada World Employmentand Social Outlook - Trends 2015, a economia mundial continua a se expandir a taxas bem menores que antes da crise global e não tem sido capaz de fechar os hiatos sociais e no emprego que surgiram a partir daí. Segundo o estudo, o crescimento continua frágil devido, entre outros fatores, à falta de demanda agregada, crescimento da desigualdade, queda do crescimento da força de trabalho e estagnação na zona do Euro. Estimativas dão conta de que, se fosse seguida a tendência pré-crise, seriam 61 milhões de empregos a mais em 2014. O emprego global cresceu a uma média de 1,7\% ao ano entre 1991 e 2007, mas somente 1,2\% de 2007 a 2014 e, em 2014, a taxa de desemprego global atingiu 5,9\%, tendo caído significativamente nos Estados Unidos, Reino Unido e em menor escala em outros países da União Europeia (a previsão é de alguma melhora nessa região). Na América Latina e Caribe, diversos países têm sofrido aumento do desemprego, contrastando com as taxas altas de criação de emprego anteriores. Seguindo a tendência atual, o desemprego global continuará a crescer com a expansão da força de trabalho.

Essa escassez de empregos também se reflete em participações mais baixas no mercado de trabalho da população em idade ativa: a participação da força de trabalho hoje ainda é $0,7 \%$ mais baixa que em 2007. As tendências de longo prazo mostram uma redução ainda maior até 2030 . 


\subsection{As Evidências Analíticas}

Segundo a interpretação dada pelo cientista político americano Marshall Berman, no contexto da moderna Sociedade do Trabalho:

o fator crucial para pertencer a essa classe não é trabalhar numa fábrica nem trabalhar com as mãos, tampouco ser pobre. Tudo isso pode mudar junto com as flutuações dos estoques, das demandas, da tecnologia e da política. A condição crucial é a necessidade de vender o seu trabalho para o capital poder sobreviver, a necessidade de mudar sua personalidade para pô-la à venda - de se olhar no espelho e perguntar ' $O$ que eu tenho que posso vender'? $E$ a permanente tensão e pavor de que, mesmo estando bem de vida hoje, você possa não encontrar ninguém que queira comprar o que você tem ou o que você é amanhã, de que o mercado mutável possa declará-lo (como já declarou a muita gente) imprestável, de que venha a se perceber física e metafisicamente sem teto e à mercê do frio (BERMAN, 2001, p. 287-288).

Ricardo Antunes seguindo a trilha de Marx afirma que o trabalho deveria ser considerado, ao contrário do que ocorre com o trabalho abstrato, como "fonte de toda riqueza e de toda a cultura" (MARX, 2004, p. 126). Na medida em que o gênero humano

põe em movimento as forças naturais pertencentes à sua corporalidade, braços e pernas, cabeça e mão, a fim de apropriar-se da matéria natural numa forma útil para sua própria vida. Ao atuar, por meio desse movimento, sobre a natureza externa a ele e ao modificá-la ele modifica, ao mesmo tempo, a sua própria natureza (ANTUNES, 2006, p. 36).

O trabalho, pois, se constituindo como condição natural da vida humana, no seu intercâmbio orgânico com a natureza. Para se apropriar da matéria natural de forma útil para a sua própria vida; "ao atuar, por meio desse movimento, sobre a Natureza externa a ele e ao modificá-la, ele modifica, ao mesmo tempo, sua própria natureza". (MARX, 1983, p. 149-150)

Nesta mesma linha, admite Marcuse que o trabalho deve ser encarado na sua dimensão ontológica, "isto é, um conceito que apreende o ser da própria existência humana como tal". (MARCUSE, 1988, p. 10) Não aceita versão dada pela moderna ciência do trabalho, posto que não englobaria os seus caracteres fundamentais e revela apenas o seu penoso "da caracterização como fardo". Por isso Reivindica um trabalho libertado da 
alienação e da coisificação, "para que ele se torne novamente aquilo que é conforme sua essência: a realização efetiva, plena e livre do homem como um todo em seu mundo histórico" (MARCUSE, 1988, p. 44). Ou como aparece, em Geörgy Lukács, enquanto ontologia do ser social.

\section{O DIÁlOgO DO DIREITO DO TRABALHO COM OUTROS CAMPOS DAS CIÊNCIAS} HUMANAS

\subsection{O Caráter Histórico e não Transhistórico da Supremacia do Trabalho} Livre/Subordinado como Centro de Referência da Sociabilidade e a priori das Teorizações no Direito do Trabalho

O texto já deixou transparecer a negligência da doutrina clássica em não dialogar com outros campos dos chamados saberes sociais ou culturais. Talvez porque isso possa manter escondido o elemento ideológico que lhe dá sustentação - o trabalho vendido comprado separado da vida.

Segundo Richard Sennett se deve

a Max Weber a militarização da sociedade civil, a partir do final do século XIX. O impacto de suas ideias é marcante na organização, como exércitos, das corporações modernas e em que todos tinham, em seu lugar e em cada lugar, uma função definida. Foi inicialmente na Alemanha de Otto Vonn Bismark que este modelo militar começou a ser experimentado nas empresas e instituições da sociedade civil. Isso, nome da paz, para preservar a própria revolução e legitimar os fundamentos da política ou do capitalismo social, ou seja, "por mais pobre que seja o trabalhador que sabe que ocupa uma posição social bem estabelecida estará menos propenso a se revoltar do que aquele que não tem uma noção clara de sua posição na sociedade (SENNET, 2006, p. 27-28).

Já André Gorz retorna à filosofia grega para justificar o trabalho enquanto invenção da modernidade e para lembrar Marx, Weber e Durkheim. Neste último, reconhece que o seu conceito de "solidariedade orgânica" não existe como uma relação vivida pelos próprios operários. Apenas, para os seus observadores externos que creem perceberem 
uma colaboração autoregulada, "ali onde, na realidade, há uma organização de tipo militar, por pré-recortes de tarefas complementares." (GORZ, 2007, p. 49).

Quando a doutrina jurídico-trabalhista clássica destaca o capitalismo nascente e põe frente a frente os trabalhos escravo/servil diante do trabalho livre/subordinado, procura, no fundo, esconder o trabalho propriamente livre, a fim de não incorporá-lo à sua dinâmica, mas para transformar o trabalho livre em trabalho subordinado. Para isso, foi preciso formular ideologicamente a "cultura do trabalho livre/subordinado" para, como já se deixou transparecer, esconder o trabalho propriamente livre, já que o mesmo aparecia como um obstáculo à dinâmica das forças produtivas. Daí, o que fazer com ele, como desqualificá-lo? Passar a considerá-lo, enquadrá-lo no conceito de preguiça, de vagabundagem e tipificá-lo nas o nas leis penais, como crime ${ }^{4}$.

O que aqui se descreve reflete bem o que os autores deste artigo vêm expressando noutras oportunidades (ANDRADE, 2014; D’ANGELO, 2014): que as versões críticas acerca da concepção burocrático-militarizante do trabalho livre/subordinado não são um patrimônio das doutrinas marxistas, socialistas ou anarquistas. A sociologia clássica a eles se referem, no mesmo sentido - em Marx, Weber e Durkheim ${ }^{6}$.

\footnotetext{
${ }^{4}$ Segundo Gorz (2007, p. 49): “Um modelo de organização fundado sobre a subdivisão funcional das tarefas não pode, portanto, fazer apelo aos trabalhadores, nem a sua consciência profissional, nem tampouco ao espírito de cooperação. Deve inicialmente recorrer à coerção - através da lei contra a "vagabundagem" e a mendicidade, obrigação de aceitar o trabalho proposto sob pena de deportação, trabalhos forçados ou morte por inação - e fazer intervir o que chamamos "reguladores prescritivos": normas de rendimento e horários imperativos, procedimentos técnicos e respeitar imperativamente. Só pode afrouxar a coerção quando puder motivar os trabalhadores, através de "reguladores incitativos", a prestarem-se de bom grado a um trabalho cuja natureza, ritmo e duração são programados de antemão pela organização da fábrica ou do escritório, um trabalho que é impossível gostar".

${ }^{6}$ Nos termos dos conceitos weberianos de "sistema burocrático racional ordenado", em que o "expediente", de um lado, e a "disciplina burocrática", do outro, exigem-se a "submissão dos funcionários" a uma "obediência rigorosa" dentro do seu labor habitual (WEBER: 1992, p. 742). Os dois últimos não negam, como Marx, o trabalho livre/subordinado, como categoria fundante da sociabilidade moderna e "a priori" de suas teorizações, mas não deixam de reconhecer a sua estrutura, tal como destacada no presente estudo. Em Durkheim (1991, p. 178-180): “o contrato não é plenamente consentido senão se os serviços trocados tiverem um valor social equivalente... Mas a força coercitiva, que nos impede de satisfazer desmedidamente os nossos desejos, mesmo desregrados, não pode ser confundida com aquela que nos retira os meios para obter a justa remuneração de nosso trabalho... Se, pelo contrário, os valores trocados não forem equivalentes, não podem equilibrar-se se qualquer força exterior tiver sido lançada na balança. Houve lesão de um lado e de outro, deste modo as vontades não puderam pôr-se de acordo sem que uma delas tivesse sofrido uma pressão directa ou indirecta, esta pressão constitui uma violência. Numa palavra,
} 
Por meio do diálogo a ser mantido ainda com a história se pode deduzir que esses modos e essas as relações de produção foram instituídos a partir da modernidade. Logo, trata-se de um fenômeno datado e não transhistórico.

Para confirmar esta hipótese o artigo se refere Marx e Engels, pois os mesmos, em 1848, reconheceram o caráter historicamente revolucionário da burguesia, já que a mesma sempre que assumia o poder, "destruiu todas as relações feudais, patriarcais, idílicas. Estilhaçou, sem piedade, os variegados laços feudais que subordinavam o homem a seus superiores naturais" (MARK e ENGELS, 2012, p. 27). Também foram capazes de compreender que a burguesia não existiria sem revolucionar os instrumentos de produção; "portanto, as relações de produção; e assim o conjunto das relações sociais" (Idem, p. 28). Admitiram, ainda, que "pela exploração do mercado mundial, a burguesia tornou cosmopolita a produção e o consumo de todos os países" (MARK e ENGELS, 2012, p. 29). Foi esta classe quem estabeleceu uma ruptura que muda, desloca o destino da humanidade. Impactante a compreensão que Marx e Engels tiveram daquele momento histórico, em que todos os instrumentos de produção, facilitados pelas comunicações promoveram aquelas rupturas. Por isso assinaram:

em apenas um século de sua dominação de classe, a burguesia criou forças de produção mais imponentes e mais colossais que todas as gerações precedentes. 0 domínio das forças naturais, o maquinismo, as aplicações da química à indústria e à agricultura, a navegação a vapor, as ferrovias, o telégrafo, o desbravamento de continentes inteiros, a canalização de rios, o aparecimento súbito de populações que século anterior se poderia prever que tais forças produtivas cochilavam no seio do trabalho social? (MARX e ENGELS, 2012, p. 29).

\footnotetext{
para que a força coercitiva do contrato esteja completa, não basta que tenha sido objeto de um consentimento expresso; deve ainda ser justa, e não é justa apenas por ter sido verbalmente consentida... Sem dúvida, seu mérito desigual fará que os homens ocupem situações desiguais na sociedade... Toda superioridade tem o seu reverso sobre a maneira como os contratos se estabelecem; se portanto ela não está ligada à pessoa dos indivíduos, aos seus serviços sociais, ela falseia as condições morais da troca. Se uma classe da sociedade é obrigada para viver, a fazer aceitar os seus serviços por qualquer preço, enquanto a outra pode deixar de o fazer, graças aos recursos de que dispõe e que todavia não são necessariamente devidos a qualquer superioridade social, a segunda dita injustamente a lei à primeira. Por outras palavras, não pode haver ricos e nobres por nascimento sem que haja contratos injustos.
} 
Seguindo este mesmo itinerário, admite Leo Huberman, que "o crescimento da população, as revoluções nos transportes, agricultura e indústria - tudo isso estava correlacionado. Agiam e reagiam mutuamente. Eram forças abrindo um mundo novo" (HUBERMAN, 1986, p. 174). Mesma compreensão admitida por Eric J. Hobsbawm, para quem "o triunfo global do capitalismo é o tema mais importante da História nas décadas que se sucederam a 1848", uma vez que "na década de 1860, uma nova palavra entrou no vocábulo econômico e político do mundo: o capitalismo" (HOBSBAWM, 2009, p. 21).

Repita-se o Direito do Trabalho é, pois, um ramo do conhecimento jurídico que tem uma origem datada e não trans-histórica. Segundo Koselleck, o "século XVIII é a antecâmara da época atual, cuja tensão se acentuou progressivamente deste a Revolução Francesa, que afetou o mundo inteiro, extensivamente, e todos os homens, intensivamente" (KOSELLECK,1999, p. 10).

Estas as razões pelas quis a função política surgida no seio do pensamento e nas aspirações da burguesia, bem como papel que ela desempenhou, no âmbito do Estado Absolutista, foram capazes de elaborar um significado político para o lluminismo. Significado que forçou a necessidade de se "indagar sobre a estrutura da primeira vítima da Grande Revolução, o Estado Absolutista, cujo desaparecimento possibilitou o desdobramento da modernidade utópica" (KOSELLECK,1999, p. 11).

Os autores deste artigo não pretendem revolver a peleja sobre uma reinterpretação categorial do marxismo. Reafirmam apenas o argumento lançado por Moishe Postone, segundo o qual uma crítica do capitalismo não pode ficar condicionada a uma noção transhistórica de "trabalho", já que o mesmo deve ser encarado como possuidor de um caráter socialmente determinado e específico da formação social capitalista. Uma qualidade específica elucidada na concepção de Marx - do "duplo caráter" do trabalho no capitalismo. Sobre esta perspectiva determina-se, de maneira adequada, o valor como uma forma historicamente específica de riqueza e de relações sociais e mostrar que o 
processo de produção incorpora tanto as "forças" quanto as "relações" de produção, e não se limita a corporificar somente as forças de produção.

\begin{abstract}
Vou fazê-lo demonstrando, de acordo com a análise de Marx, que o modo de produzir no capitalismo não é simplesmente um processo técnico. É, na verdade, moldado pelas formas objetivadas das relações sociais (valor, capital). Daí se torna claro que a crítica marxiana é uma crítica do trabalho no capitalismo, não apenas uma crítica da exploração do trabalho e do modo de distribuição, e que a contradição fundamental da totalidade capitalista deve ser vista como intrínseca ao reino da produção em si, e não apenas uma contradição entre as esferas de produção e distribuição (POSTONE, 2014, p. 148).
\end{abstract}

Este é o momento histórico em que o trabalho livre/subordinado se legitima e se universaliza como locus privilegiado da sociabilidade e como a priori das teorizações, no âmbito da sociologia clássica.

\title{
4.1.2 Os rituais do sofrimento e a morte lenta no trabalho como característica da compra e venda da força de trabalho. Para um diálogo com a teoria organizacional crítica
}

Os estudos e pesquisas que os autores deste texto vêm desenvolvendo procuram demonstrar que a Divisão Social do Trabalho concebida a partir de Adam Smith - desde a era pré-capitalista -, consolidada por meio da chamada Administração Científica Fordista/Taylorista - até chegar-se a configuração de sua passagem para o modelo de Acumulação Flexível tem, como pressuposto, estabelecer um controle e um domínio, um vigar e um punir que envolve os fundamentos do Direito do Trabalho, em particular, mas envolve também os demais ramos do direito.

Para uma visão analítica abrangente sobre o trabalho humano se torna imprescindível um diálogo do pesquisador com este outro ramo do saber social. Especialmente, para estabelecer um confronto entre as teorias organizacionais conservadoras e as teorias organizacionais críticas, uma vez que, por meio destas últimas, é possível desvendar os mistérios da prevalência, nas relações jurídico-trabalhistas, do 
trabalho militarizado e revelar os sentidos da Cultura e do Poder nas organizações. ${ }^{7}$ Cultura e Poder que acompanham os primórdios da chamada divisão social do trabalho até chegar-se às organização hipermoderna - ou organização-droga, em que o trabalhador aparece como o ser amado e detestado, passando a assumir uma postura ambivalente em relação a ela.

É exatamente na teoria organizacional crítica que o pesquisador toma conhecimento dos mecanismos de controle e a maneira como a organização se torna, para o empregado, a fonte de prazer e, ao mesmo tempo, alimenta e fixa sua angústia, por tornar-se dependente dela, no sentido pleno da palavra. Para Pagès, Bonetti, Gaulejac e Descendre, "não apenas para sua existência material, mas também para a integridade de sua própria identidade" [...] "A transação entre o indivíduo e a organização funciona através desse par ambivalente: o prazer e a angústia" (GAULEJAC e DESCENDRE, 1987, p. $147)^{8}$.

Por meio desta visão crítica da cultura e do poder das organizações torna-se possível desmitificar a evangelização, a glorificação do trabalho subordinado, na medida em que se procura acompanhar a sua evolução histórica, o grau de sofisticação do controle

\footnotetext{
${ }^{7}$ Versão analítica resulta de uma teoria do poder nas organizações capazes de revelar os seus métodos de dominação sobre os indivíduos, sobretudo pelas organizações hipermodernas. Foi concebida por Max Pagès, Vicent de Gaulejac, Michel Bonetti e Daniel Descendre (1987), por meio de uma obra original foi editada em 1979. Teoria do poder e da organização que foi elaborada a partir de um estudo concreto sobre o funcionamento de uma empresa multinacional - intitulada, na pesquisa, como TLTX -, a fim de compreender as relações entre o econômico, o político, o ideológico e o psicológico. Seu objeto era conhecer como essas organizações hipermodernas difundem sua ideologia, a sua religião, estruturadas nas políticas de recursos humanos e conseguem a adesão dos seus membros, através da influência sobre estruturas inconscientes por intermédio das quais os indivíduos se ligam a elas. Revela também a maneira como as pessoas se tornavam escravizadas pela organização e, no sentido sociológico, como essa escravidão tem uma característica de droga - prazer e sofrimento.

${ }^{8}$ Esta versão - organização-droga - corresponde, enquanto droga, a um corpo estranho que se mescla ao organismo e provocam efeitos maiores que escampam ao seu controle - corpo estranho que passa a se tornar parte integrante do organismo e que o controla. Uma imagem que, na linguagem psicanalista designa conceitos de identificação, de projeção e de introjeção. "Pela projeção sobre o objeto, de partes de si, de seus impulsos e de seus medos reprimidos, o indivíduo se torna uma parte do objeto, que vai então expressar, em seu lugar, seus medos e seus desejos e lhe permitir de os viver inconscientemente sem os assumir. Inversamente, o objeto assim investido pelo inconsciente do indivíduo é introjetado, ele toma o lugar das emoções reprimidas no inconsciente do sujeito, tornando-se parte dele. O resultado deste duplo processo é a identificação. Produz-se uma colagem entre o inconsciente individual e o objeto que se torna indissociáveis, sem que o indivíduo tenha consciência do processo que conduz à identificação: 'faço parte da TLTX, como TLTX faz parte de minha vida'” (Idem, p. 147).
} 
instituído, desde a Administração Científica - de Ford e Taylor - para chegar-se ao Onhismo, ao Toytismo, ao Volvoismo, ao Círculo de Controle de Qualidade - CQCs -, aos sistemas de produção Just-in-time e kanban, à Ergonomia, à Reengenharia, ao Planejamento Estratégico, enfim, a todas as experiências e práticas organizacionais voltadas para racionalidade, à eficiência produtiva e ao controle do trabalho humano.

Mas, não há dúvida que existe um destaque para as escolas francesas. ${ }^{9} \mathrm{O}$ psicanalista Christophe Dejours afirma que os resultados das recentes pesquisas etiológicas confirmam a deterioração da saúde mental no trabalho e que ela está relacionada à organização do trabalho e, sobretudo, às novas estratégias organizacionais. Existe uma considerável pressão produtiva que resulta da evolução dos métodos de organização do trabalho. Este fator, por si só, provoca um isolamento, uma solidão e o aumento das patologias mentais resultantes do trabalho. Estes métodos organizacionais, por outro lado, instalam um individualismo exacerbado, deslealdade, a desconstrução de convício, em vez da confiança, a lealdade e a solidariedade. Tudo isso produz uma “implacável solidão em meio à multidão” (DEJOURS, 1992, p. 50).

Ao prefaciar a obra escrita por Vicente de Gualejac, admite Pedro Bendassolli que a versão conservadora da gestão se consolidou como uma ideologia dominante do nosso tempo, sobretudo, quando é combinada com a emergência de práticas gerencialistas, posto que se constitui como poder característico da sociedade hipermoderna. ${ }^{10}$

\footnotetext{
9 O famoso Tratado de Sociologia do Trabalho (1978), cuja primeira edição é de 1961, reúne vários estudos considerados, por Alain Touraine (1967, p. 9), como de psicossociologia da empresa. Antecipava ele uma discussão que começava retardada por mais de trinta anos. Mas, não se vincularia mais e apenas às técnicas de organização e desvinculada do desenvolvimento econômico. Para ele, "seria indispensável analisar as transformações que haviam sido desencadeadas nas relações da empresa e do sistema econômico o social; examinar, a partir do movimento de concentração industrial, as transformações ocorridas na propriedade e no controle, na direção e na organização da empresa" (TOURAINE, 1967, p. 9).

${ }^{10}$ Gaulejac (2007, p. 33) cita Nicole Aubert, a partir de um livro escrito em 2004 e afirma: “A noção de organização “'hipermoderna' foi proposta por Max Pagès (Pagès et. Al. 79) na pesquisa que realizamos juntos sobre o poder em uma grande multinacional. A presente obra se inscreve na filiação desse trabalho, cujas hipóteses, vinte e cinco anos depois, não foram desmentidas pelos fatos".
} 
Embora se trate de um tema negligenciado pela velha doutrina jurídico-trabalhista, ele já vinha sendo disseminado pelos teóricos das organizações vinculados à teoria crítica, desde a década de 50 do século passado. Georges Friedmann (1964) denunciou, nas pesquisas realizadas na década de cinquenta daquele século, a existência do trabalho em migalhas, resultante da automação e do progresso técnico, na medida em que ele poderia contribuir para a degradação do homem.

Estas as razões pelas quais se tornarem imprescindíveis a articulação entre a teoria jurídico-trabalhista crítica e os estudos psicossociais das organizações hipermodernas, objetivando uma compreensão da própria estrutura do capitalismo flexível. Daí poder-se também compreender a flexibilização e a desregulamentação das relações de trabalho.

\subsubsection{A reconfiguração das lutas sindicais. Um diálogo com os movimentos sociais e as teorias dos movimentos sociais}

Outra variável relevante da obsolescência da doutrina clássica diz respeito a sua produção, no âmbito das relações sindicais ou coletiva de trabalho.

Impacta este apatia, na medida em que o Direito do Trabalho surge da luta de classe, da luta operária. Logo, as relações sindicais ou coletivas deveriam ter preferência, na literatura jurídico-trabalhista. Num manual de Direito do Trabalho com duas mil páginas, não há duzentas sobre essas relações. Quando se fala, por exemplo, sobre a história da formação operária brasileira, nada existe sobre a sua primeira fase, que surgiu nas últimas décadas do século XIX e existiu, como predominante, até a década de vinte do século vinte - o sindicalismo anarquista. ${ }^{11}$

Mas, o aspecto mais importante diz respeito à própria concepção do fenômeno coletivo enquanto luta abstrata, que envolve categorias - profissionais e econômicas - e

\footnotetext{
${ }^{11}$ A propósito, ver o livro Fernanda Barreto Lira (2008), A Greve e os Novos Movimentos Sociais: Para além da dogmática jurídica e da doutrina da OIT. A autora abre uma seção sobre a história do anarquismo e a luta operária, no Brasil.
} 
apareceu para romper e desmitificar os pressupostos da própria filosofia liberal, centrada no individualismo contratualista. Esta vertente filosófica considerava e considera o "coletivo" como a soma dos interesses individuais. A greve é uma prova desta ruptura. Nela existe uma categoria pelejando com outra categoria. Não é possível, por meio dela, identificar, somar, registrar as pessoas nela envolvidas.

Por fim, quando trata das lutas coletivas, privilegia as lutas reformistas desencadeadas em favor das melhorias das condições de vida e de trabalho a serem reconstituídas no interior das organizações -, mas, pouco diz a respeito das lutas emancipatórias e contra-hegemônicas.

Talvez aqui resida, mesmo diante da crise estrutural e das metamorfoses em curso, a sua falta de diálogo com os novos movimentos sociais e com as teorias dos movimentos sociais. Implica, principalmente, debruçar-se sobre uma análise específica, no que diz respeito às ações coletivas e aos movimentos sociais, ou melhor, às Teorias dos Movimentos Sociais e seus paradigmas - clássicos e contemporâneos, bem como às possibilidades de sua reconstrução. ${ }^{12}$

Mas, esta versão analítica se tornou prioritária para Programa de Pós-Graduação em Direito da UFPE, na linha de pesquisa Direito do Trabalho e Teoria Social Crítica. Sobretudo, no sentido de reconstruir os estudos que dizem respeito aos paradigmas dos movimentos sociais, no âmbito específico das relações coletivas ou sindicais de trabalho.

A complexidade e as metamorfoses que atingiram o mundo do trabalho, apesar de não terem eliminado os paradigmas tradicionais que sedimentaram os movimentos sociais decorrentes do mundo do trabalho, não podem ser vistos sem o acompanhamento de sua evolução e, sobretudo, um acompanhamento que envolva a sua dúplice perspectiva: serem eles movimentos ao mesmo tempo reformistas e emancipatórios. Uma visão

\footnotetext{
${ }^{12}$ No livro “Movimentos sociais. Paradigmas clássicos e contemporâneos, Maria da Glória Gohn traça importante a cartografia sobre estas teorias. A autora trata especificamente da experiência brasileira no livro Histórias dos Movimentos e Lutas Sociais: a construção da cidadania dos brasileiros, publicado pelas Edições Loyola.
} 
analítica que exige, repita-se, um diálogo com as teorias dos movimentos sociais. (LEHER; SETÚBAL, 2005) Do mesmo modo, para localizar, dentre as teorias dos movimentos sociais, qual a que melhor expressa um identidade com os movimentos forjados no interior da luta operária. Deixam os autores deste artigo a sua opção pela vertente que parte de seguinte narrativa: o modo de produção capitalista e a subordinação da força de trabalho ao capital. Narrativa que pode articular todos os movimentos sociais - dos excluídos do trabalho, dos clandestinos, dos discriminados por questões de gênero, de cor, etc. -, conforme defendem Carlos Montaño e Maria Lúcia Duriguetto (2011) em torno daquela dúplice perspectiva.

\section{PARA UMA RECONFIGURAÇÃO TEÓRICO-DOGMÁTICA DO DIREITO DO TRABALHO, A PARTIR DO DIÁLOGO INSTITUÍDO COM OUTROS RAMOS DAS CIÊNCIAS SOCIAIS}

O texto deixou transparecer que o trabalho contraditoriamente livre/subordinado, enquanto objeto do Direito do Trabalho, encontra-se refutado por meio de evidências empíricas e analíticas. Procurou demonstrar a necessidade de se retomar a memória histórica dos movimentos operários, para restabelecer a sua dúplice perspectiva reformista/revolucionária, haja vista o desprezo da velha doutrina para com os movimentos emancipatórios e contra-hegemônicos.

Mas, torna-se necessário também, em face das metamorfoses em curso e da emergência dos movimentos sociais que se espalham por todo o planeta, promover, por meio das teorias dos movimentos sociais, uma articulação dos movimentos tipicamente operários com os demais movimentos sociais, inclusive, para incluir nas suas pautas tradicionais outras reivindicações que dizem respeito à sociedade civil como um todo.

Este tem sido o esforço acadêmico que move os autores deste artigo, quando se propuseram a problematizar, refutar e propor gnosiologicamente novos fundamentos para o Direito do Trabalho (ANDRADE, 2005; ANDRADE, 2008; ANDRADE, 2014; DANGELO, 
2014; DANGELO, 2016), a partir de uma pauta hermenêutica distinta e de outros fundamentos teórico-filosóficos.

Um campo do conhecimento jurídico que buscará a proteção de todas as possibilidades ou alternativas de trabalho e renda compatíveis com a dignidade humana, especialmente o trabalho livre - e não apenas o trabalho subordinado. Do mesmo modo, a retomada de uma versão analítica que reúna as lutas no seu duplo sentido: reformista/revolucionária.

No contexto daquelas perspectivas, para superar a resistência e a obsolescência da doutrina jurídico-trabalhista clássica, torna-se também imprescindível que os pesquisadores vinculados ao Direito do Trabalho se articulem com os outros ramos dos chamados saberes sociais ou culturais, quando os mesmos se ocuparem do trabalho humano e, por fim, incluam nas suas pautas e pesquisas os novos movimentos sociais e as teorias dos movimentos sociais.

Reforçar, por fim, que a universalização/legitimação do Direito do Trabalho não é um fenômeno transhistórico, mas datado. Surge com o aparecimento do modo de produção capitalista e das relações de produção por ele instituídas e constituídas por meio da subordinação da força do trabalho ao capital. Uma dominação de classe que perdura ainda mais sofisticada, sobretudo em dois sentidos: na esfera da dominação dos meios de produção; no alargamento e na sofisticação da captura da subjetividade, por meio do trabalho abstrato, alienado.

Ainda bem que os novos movimentos sociais já começaram e vem se espalhando por todo o planeta. Para os autores deste artigo, espera-se que eles possam se unir em torno de uma narrativa. Aquela capaz de revelar a maneira como, hoje e ontem, se desencadeiam, para todos os lados, a opressão e as patologias sociais contemporâneas, ou seja: o modo de produção capitalista e a subordinação da força do trabalho ao capital. 


\section{CONCLUSÃO}

O Direito do Trabalho se constituiu ramo autônomo da ciência jurídica na medida em que elegeu, como seu objeto, o trabalho contraditoriamente livre/subordinado.

Trata-se, pois, de um campo do direito que se legitima e se universaliza para disciplinar aquele modelo de trabalho que surge na modernidade, por meio da ascensão da burguesia ao poder - quando a mesma destrói o absolutismo monárquico, em que os poderes se encontravam nas mãos do clero e da nobreza. É das entranhas da Revolução Industrial que surgem e se estabelecem rupturas políticas, econômicas e sociais e, por seu turno, alterações da subjetividade, da estática, da linguagem, da sociedade, do estado e do direito.

Em termos do binômio gramsciano ideologia/hegemonia, passou a estabelecer um contraponto entre trabalho escravo/servil e trabalho livre/subordinado, este aparecendo este como lócus privilegiado da sociabilidade e a priori das teorizações no campo das ciências sociais em geral e do Direito do Trabalho, em particular.

Direito que erigiu seus fundamentos - fontes, princípios, denominação, natureza jurídica, eficácia no tempo e no espaço, hermenêutica e esfera de aplicação, etc.,-- tendo como ponto de partida o Princípio da Proteção, por intermédio do qual se busca nivelar os sujeitos desta relação jurídica especial - empregador e empregado -, uma vez que as mesmas nascem ontologicamente desiguais.

O texto demonstrou que aquele objeto se encontra refutado, por dois motivos: as evidências empíricas e as evidências analíticas. As primeiras demonstram haver uma metamorfose no mundo do trabalho. Se o Direito do Trabalho veio para proteger a maioria da população economicamente ativa, o que havia ocorrido no auge do Estado do BemEstar e do Pleno Emprego, agora não consegue proteger sequer a metade daquele universo. Os demais se encontram no trabalho clandestino ou alcançado pelo desemprego estrutural. As segundas apontam para o desvendamento ideológico instituído por meio do 
Modo de Produção Capitalista que desencadeia e institui a subordinação da força do trabalho ao capital.

Na medida em que a teoria jurídico-trabalhista crítica estabelece um diálogo com os outros ramos dos chamados saberes sociais ou culturais, é possível reconfigurar o objeto deste ramo do direito, a partir da prevalência do trabalho como ontologia do ser social, para que prevalece, como seu objeto, o trabalho propriamente livre.

Este mesmo diálogo permite a adoção de outra pauta hermenêutica que restaura os fundamentos das lutas operárias, em sua dúplice perspectiva - reformista/revolucionária. Neste contexto, envolve as lutas operárias com os novos movimentos sociais e possibilita que o pesquisador conheça e escolha uma ou várias correntes das chamadas teorias dos movimentos sociais.

Os autores deste artigo deixam transparecer a sua opção pelo reconhecimento de todos os movimentos sociais que se dirigem à emancipação social. Mas, reconhecem que os mesmos devem partir de uma narrativa que os envolva, ou seja: o modo de produção capitalista e a subordinação da força do trabalho ao capital.

\section{REFERÊNCIAS}

ADEODATO, João Maurício. Ética e retórica. Para uma teoria da dogmática jurídica. São Paulo: Saraiva, 2012.

ANDRADE, Everaldo Gaspar Lopes de. Direito do trabalho e pós-modernidade. Fundamentos para uma teoria geral. São Paulo: LTr, 2005.

LTr, 2008.

Princípios de direito do trabalho. Fundamentos teórico-filosóficos. São Paulo:

O direito do trabalho na filosofia e na teoria social crítica. Os sentidos do trabalho subordinado na cultura e no poder das organizações. São Paulo: LTr, 2015. 
ANTUNES, Ricardo (Org). A dialética do trabalho. Escritos de Marx e Engels. São Paulo: Expressão Popular, 2004.

ANTUNES, Ricardo. Os sentidos do trabalho: ensaio sobre a afirmação e a negação do trabalho. São Paulo: Boitempo, 2006.

BAUMAN, Zygmunt. Mal-estar na pós-modernidade. São Paulo: Jorge Zahar, 1998.

BERMAN, Marshall. Aventuras no marxismo. São Paulo: Companhia das Letras, 2001.

D'ANGELO, Isabele de Moraes. A subordinação da força de trabalho ao capital. Para ampliar os cânones de proteção e os princípios do Direito do Trabalho. São Paulo: LTr, 2014.

A reconfiguração teórico-dogmática das teorias jurídicas do salário: para além da subordinação e da compra e venda da força de trabalho. Recife: Programa de Pósgraduação em Direito. Tese de doutorado. Texto avulso, 2016.

DEJOURS, Christophe. A loucura do trabalho: estudos de psicopatia do trabalho. São Paulo: Cortez, 1992.

DURKHEIM, Emile. A divisão do trabalho social. vol.II. Lisboa: Editorial Presença, 1991.

FEITOSA, Enoque. Forma Jurídica e Método Dialético: a crítica marxista ao Direito. In: Marxismo, realismo e direitos humanos. João Pessoa, Editora Universitária da UFPB, 2012, p. 107-157.

FRIEDMANN, Georges; NAVILE, Pierre. Tratado de sociología del trabajo. México: Fondo de Cultura Económica, 1978.

FRIEDMANN, Georges. O trabalho em migalhas. São Paulo: Perspectiva, 1972.

GAULEJAC, Vincent. Gestão como Doença social, ideologia, poder gerencialista e fragmentação social. Aparecida: SP: Idéias \& Letras, 2007.

GOHN, Maria da Glória. Teorias dos movimentos sociais. Paradigmas clássicos e contemporâneos. São Paulo: Edições Loyola, 1997.

História dos movimentos sociais. A construção dos movimentos e lutas sociais dos brasileiros. São Paulo: Edições Loyola, 1995.

GOHN, Maria da Gloria; BRINGEL, Breno M. (Orgs). Movimentos sociais na era da globalização. Petrópolis, RJ: Vozes, 2012.

GORZ, ANDRÉ. Metamorfoses do trabalho. Crítica à Razão Econômica. São Paulo: Annablume, 2007. 
O Imaterial. Conhecimento, valor e capital. São Paulo: Annablume, 2007.

KASHIURA JR., Celso Naoto. Sujeito de direito e capitalismo. São Paulo: Outras Expressões, 2014.

KOSELLECK, Reinhart. Crítica e crise. Uma contribuição à patogênese do mundo burguês. Rio de Janeiro: Contraponto, 1999.

HOBENSBAWM, Eric. A era do capital. São Paulo: Editora Paz e Terra, 2009.

HUBERMAN, L. História da riqueza do homem. Rio de Janeiro: Zahar, 1984.

LESSA, Sérgio. Trabalho e proletariado no capitalismo contemporâneo. São Paulo: Cortez, 2007.

LEHER, Roberto; SETÚBAL, Mariana (Orgs). Pensamento crítico e movimentos sociais. Diálogos para uma práxis. São Paulo: Cortez, 2005.

LUKÁCS, Gyorgy. Ontología del ser social. Buenos ASires, Herramienta, 2004.

MARCUSE, Herbert. Cultura e sociedade. vol. 2. São Paulo: Paz e Terra, 1998.

MARX, Karl. O CAPITAL. Crítica da Economia Política. Livro 1, vol. 1. O Processo de produção do Capital. Rio de Janeiro: Civilização Brasileira, 2003.

Salário, precio y ganancia. Moscu: Editorial Progreso, 1979.

MARX, K; ENGELS, F. Manifesto do Partido Comunista. In. Karl Marx e ENGELS, Friedrich. Obras escolhidas. São Paulo: Alfa-omega, 1953.

MARX, Karl. Crítica ao Programa de Gotha. In: Ricardo Antunes (Org). A dialética do trabalho. Escritos de Marx e Engels. São Paulo: Expressão Popular, 2004.

MELHADO, Reginaldo. Poder e Sujeição. Os fundamentos da relação de poder entre capital e trabalho e o conceito de subordinação. São Paulo: LTr, 2003.

MONTAÑO, Carlos; DURIGUETTO, Maria Lúcia. Estado, classe e movimento social. São Paulo: Cortez, 2011.

PAGÈS, Max; BONETTI, Michel; GAULEJAC, Vicent; DESCENDRE, Daniel. O poder das organizações: a dominação das multinacionais sobre os indivíduos. São Paulo: Atlas, 1987.

POSTONE, Moishe. Tempo, trabalho e dominação social. São Paulo: Boitempo, 2014. POPPER, Karl. A lógica da pesquisa científica. São Paulo: Cultrix, 1972. 
SENNETT, Richard. A cultura do novo capitalismo. São Paulo: Record, 2006.

WEBER, Max. Economía y sociedad. México: Fondo de Cultura Económica, 1992.

ANDRADE, Everaldo Gaspar Lopes de; D'ANGELO, Isabele Bandeira de Moraes. Direito do trabalho e teoria social crítica: um diálogo indispensável entre este campo do direito e os demais saberes sociais. RBSD - Revista Brasileira de Sociologia do Direito, v. 3., n. 1, p. 71-96, jan./abr. 2016.

Recebido em: 05/07/2016

Aprovado em: 24/07/2016 